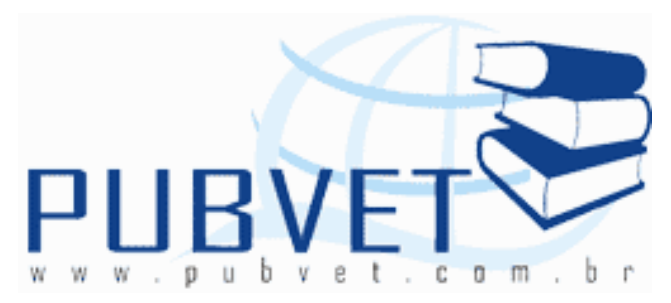

PUBVET, Publicações em Medicina Veterinária e Zootecnia.

\title{
Estudo anatômico do encéfalo de avestruz (Struthio Camelus)
}

Karina do Valle Marques ${ }^{1}$, Ricardo Bandeira ${ }^{2}$, Gisele Saviani ${ }^{3}$, Vanessa Belentani Marques $^{3}$, Mariana Matera Veras ${ }^{4}$

${ }^{1}$ Universidade Federal do Tocantins ; Docente do Curso de Medicina - Morfologia

${ }^{2}$ Especialista em Processos de Aprendizagem no Ensino Superior - Biomédico

${ }^{3}$ Universidade de São Paulo - Faculdade de Medicina Veterinária e Zootecnia Veterinária

${ }^{4}$ Laboratório de Poluição Atmosférica Experimental (LIM05), Departamento de Patologia Faculdade de Medicina, Universidade de São Paulo, São Paulo - Bióloga

\section{Resumo}

Estudou-se a morfologia do encéfalo de avestruz (Struthio Camelus), buscando comparar estes achados com outras espécies de aves já descritos. Foram utilizados seis encéfalos de aveztruz, clinicamente sadios provenientes de um mesmo criadouro localizado no Estado de São Paulo, que tinha como finalidade a venda de animais. Retirou-se a calota craniana e o encéfalo foi exposto. Em seguida os animais fixados em solução de formaldeído a $10 \%$ e posteriormente procedeu-se a dissecação. Considerando os dados da literatura consultada, relativos a outras espécies de aves, o encéfalo do avestruz mostra disposições características de algumas de suas estruturas que são consideradas indicadores 
MARQUES, K.V. et al. Estudo anatômico do encéfalo de avestruz (Struthio Camelus). PUBVET, Londrina, V. 7, N. 7, Ed. 230, Art. 1521, Abril, 2013.

de evolução, tais sejam lobo óptico, origem aparente de nervos cranianos, fissuras lobulares do cerebelo.

\section{Anatomical study of the encephalon of the ostrich (Struthio camelus)}

\section{Abstract}

The morphology of the encephalon of the ostrich was studied in order to compare the findings with previous reports described in avian. Six ostrich encephalon of healthy animals from one breeding center for commercial purposes located in Sao Paulo State were used in the present study. The skull was removed in order to expose the encephalon. The specimens were then immersion-fixed in $10 \%$ formalin prior to dissection. Considering the data in the literature relative to other avian species, the ostrich brain exhibit typical features that are considered indicators of evolutionary process such as optical lobe, apparent origin of cranial nerves, cerebellum lobular fissures.

\section{Introdução}

As ratitas são aves corredoras que apresentam características anatômicas e fisiológicas que as diferenciam das aves carinatas (aves que voam), como ausência de musculatura peitoral para vôo e quilha sobre o osso esterno, ou seja, são incapazes de voar (Sick, 1997). Dentre as espécies de ratitas comercialmente exploradas, destacam-se o avestruz (Struthio camelus), o emu (Dromaius novaehollandiae) e a ema comum (Rhea americana). Com o crescimento e especialização da cadeia industrial de ratitas, especialmente do avestruz, existe uma crescente necessidade de compreender seus aspectos biológicos e fisiológicos Estes estudos são de extrema importância, principalmente levando em 
MARQUES, K.V. et al. Estudo anatômico do encéfalo de avestruz (Struthio Camelus). PUBVET, Londrina, V. 7, N. 7, Ed. 230, Art. 1521, Abril, 2013.

consideração os diversos problemas enfrentados na criação destes animais, como o manejo intensivo, aspectos reprodutivos e comportamentais (Giannoni, 1998).

Os dados bibliográficos referentes a morfologia do encéfalo de avestruzes são inexistentes, sendo que à maioria dos relatos apresentam-se genericamente para as aves em geral (galinhas - Gallus domesticus) (Baer, 1837; Zimmermann, 1891; Kupffer, 1906).

O número de publicações disponíveis sobre o encéfalo de aves adultas é escasso e as divulgações existentes são raras. O cérebro da galinha tem sido generalizado como modelo de estudo cerebral de aves e, algumas vezes, é comparado com répteis, anfíbios e mamíferos (Krabbe, 1952). Dessa maneira, devido à escassez de informações da morfologia do encéfalo de avestruz, este descreve o encéfalo de avestruz, comparando-o com o de outras aves. Estes resultados fornecem dados importantes sobre a neurologia de avestruzes, possibilitando a compreensão de sua biologia comportamental e reprodutiva.

\section{MATERIAL E MÉTODO}

Utilizamos neste trabalho 6 encéfalos de avestruzes (Struthio Camelus), sadios, que foram doados de um mesmo criadouro localizado no Estado de São Paulo, que tem como finalidade a venda de animais. A preparação das peças anatômicas foi realizada retirando-se cuidadosamente o encéfalo, da cavidade craniana, após o que procedeu-se à limpeza da peça, removendo-se os envoltórios correspondentes às meninges. No afastatamento da pia-máter, tivemos sempre o cuidado de preservar a origem aparente dos nervos cranianos. Em seguida os cérebros foram pesados em balança eletrônica. A mensuração da espessura das estruturas encefálicas (largura e comprimento) foi realizada com auxílio de um paquímero. Efetuamos observaçoes de aspectos macroscópicos da superfície externa do encéfalo, a olho nu e quando necessário, sob lupa com 
MARQUES, K.V. et al. Estudo anatômico do encéfalo de avestruz (Struthio Camelus). PUBVET, Londrina, V. 7, N. 7, Ed. 230, Art. 1521, Abril, 2013.

aumento de 10x. Realizada a descrição de aspectos macroscópicos, procedemos ao preparo de documentação mediante esquemas e fotografias.

\section{RESULTADOS}

\section{Encefalometria}

O comprimento dos encéfalos foram respectivamente $54 \mathrm{~mm}(2), 58 \mathrm{~mm}$ (2), $60 \mathrm{~mm}(1), 61 \mathrm{~mm}(1)$. A largura total de cada encéfalo foi de $45,5 \mathrm{~mm}$ (1), $46,5 \mathrm{~mm}(2), 47 \mathrm{~mm}(1), 50 \mathrm{~mm}(1), 50,5 \mathrm{~mm}$. O peso dos encéfalos variou de 30,39 a 43,90. Os valores do comprimento, largura e peso total do encéfalos são mostrados na Tabela 1.

O comprimento do telencéfalo variou de $32 \mathrm{~mm}$ a $43 \mathrm{~mm}$ e a largura variou de 42,5 a 47,5 como mostrado na Tabela 2.

O comprimento do lobo óptico variou de $11,5 \mathrm{~mm}$ a $20 \mathrm{~mm}$ e a largura variou de $10 \mathrm{~mm}$ a $12 \mathrm{~mm}$ como verificado na Tabela 3 .

O cerebelo variou em comprimento de $22 \mathrm{~mm}$ a $36 \mathrm{~mm}$ e a largura variou de $22 \mathrm{~mm}$ a $31 \mathrm{~mm}$ como mostrado na Tabela 4.

Tabela 1 - Peso expresso em gramas e medidas do comprimento e da largura expressas em milímetros, de Encéfalos de Struthio Camelus - São Paulo, 2005

\begin{tabular}{cccc}
\hline Encéfalo & Comprimento & Largura & Peso total \\
1 & 60,00 & 50,00 & 38,30 \\
2 & 58,00 & 47,00 & 37,66 \\
3 & 54,00 & 45,50 & 34,50 \\
4 & 54,00 & 46,50 & 33.77 \\
5 & 58,50 & 46,50 & 30,39 \\
6 & 61,00 & 50,50 & 43,90 \\
\hline
\end{tabular}


MARQUES, K.V. et al. Estudo anatômico do encéfalo de avestruz (Struthio Camelus). PUBVET, Londrina, V. 7, N. 7, Ed. 230, Art. 1521, Abril, 2013.

Tabela 2 - Medidas de comprimento e largura do Telencéfalo de Struthio Camelus, expressas em milímetros

\section{Telencéfalo}

1

2

3

4

5

6

\section{Comprimento}

43,00

35,00

35,00

33,5

36,00

32,00

\section{Largura}

47,50

45,50

42,5

43,5

45,00

46,00

Tabela 3 - Medidas de comprimento e largura do Lobo óptico de Struthio Camelus, expressas em milímetros

\section{Lobo óptico}

1

2

3

4

5

\section{Comprimento}

11,50

15.00

14.00

14.00

17.00

20.00

\section{Largura}

10.00

10.00

10.00

11.00

12.00

12.00

Tabela 4 - Medidas de comprimento e largura do Cerebelo de Struthio Camelus, expressas em milímetros

\section{Cerebelo}

1

2

3

4

5

6

\section{Comprimento}

36.00

22.00

32,50

32.00

22.00

28.00

\section{Largura}

25.00

25.00

31.00

22.00

22.00

25.00 
MARQUES, K.V. et al. Estudo anatômico do encéfalo de avestruz (Struthio Camelus). PUBVET, Londrina, V. 7, N. 7, Ed. 230, Art. 1521, Abril, 2013.

\section{Morfologia externa do encéfalo}

O telencéfalo é composto por dois hemisférios cerebrais, é o segmento mais proeminente do encéfalo e encobre o diencéfalo e o mesencéfalo completamente em vista dorsal. Os dois hemisférios cerebrais estão separados pela fissura longitudinal do cérebro. Na superfície dorsal do telencéfalo próximo a fissura longitudinal do cérebro verificamos duas eminências denominadas de eminência sagital. Situado lateralmente as eminências sagitais encontra-se uma depressão reconhecida como valécula. Entre o telencéfalo e o cerebelo verificamos a presença da fissura transversa do cérebro. Ainda no telencéfalo verificamos que esse apresenta uma superfície lisa, sua extremidade é arredondada, enquanto a extremidade anterior é afunilada. Na extremidade anterior do telencéfalo a face inferior apresenta uma dilatação pontiaguda contínua com o telencéfalo, denominada de lobo óptico. Na superfície ventral e dorsal do telencéfalo podem ser vistas duas dilatações alongadas reconhecidas como bulbo olfatório. As estruturas do telencéfalo são demonstradas na Figura 1.

$\mathrm{Na}$ face ventral do encéfalo o bulbo olfatório é continuo com o trato

olfatório. Ventralmente no diencéfalo são nitídos: o quiasma óptico, o nervo óptico, o tracto óptico, o túber cinéreo e a glandula pinelal (Figura 2). A glândula pineal tem formato ovalado com comprimento de $6 \mathrm{~mm}$ e $3 \mathrm{~mm}$ de espessura.

O tronco encefálico se divide em: mesencéfalo (situado cranialmente), a medula oblonga (situada caudalmente) e ponte. Não existe um limite nítido entre a medula oblonga, a ponte e o mesencéfalo. A ponte não é uma estrutura nítida no cérebro de avestruz, estando interligada com a medula oblonga. A superfície da medula oblonga é lisa e toda sua extensão é percorrida pela fissura mediana anterior que finaliza em uma depressão onde da origem ao mesencéfalo e forma os pedunculos cerebrais. As pirâmides e a decussação das pirâmides não são 
MARQUES, K.V. et al. Estudo anatômico do encéfalo de avestruz (Struthio Camelus). PUBVET, Londrina, V. 7, N. 7, Ed. 230, Art. 1521, Abril, 2013.

evidentes. Os nervos cranianos III, IV, V, VI, VII, VIII, IX, X, XI, XII são observados, sendo que o nervo trigêmeo é muito robusto.

O cerebelo de avestruz apresenta uma protuberância sagital que é semelhante a parte média do cerebelo dos mamíferos, o corpo cerebelar ou vermis (Figura 3). A superfície rostral do cerebelo do avestruz possui a impressão hemisférica e a impressão mesencefálica. O pequeno flóculo projeta-se lateralmente. O cerebelo une-se rostralmente com o mesencéfalo através do véu medular rostral. O cerebelo é subdividido por duas fissuras transversas profundas, a fissura anterior e a fissura posterior, no interior do lobo anterior, médio e posterior. O cerebelo apresenta uma organização em lóbulos que são reconhecidos como superior, médio e inferior. Cada lobo apresenta folhas cerebelares sendo que é possível identificar em cortes sagitais mediano a língula, o lobo central, o cúlmen, o declive, o folium, o túber, a pirâmide, a úvula e o nódulo.

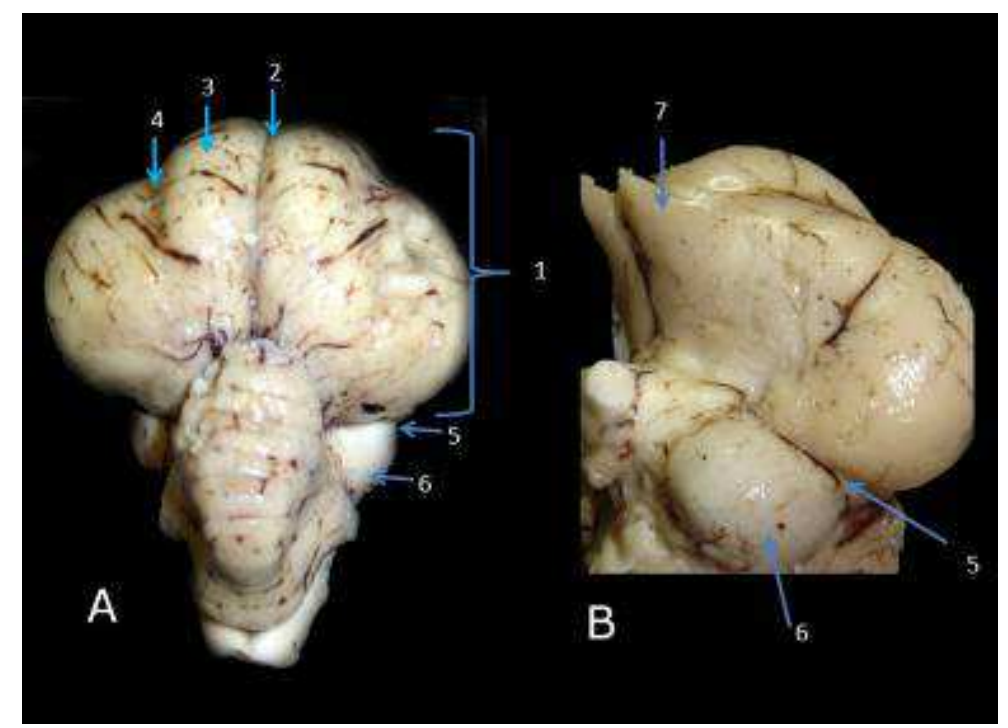

Figura 1. Encéfalo de avestruz evidenciando o telencéfalo. A) vista dorsal (1) Hemisférios cerebrais, (2) Fissura Longitudinal do cérebro, (3) Eminência Sagital, 
MARQUES, K.V. et al. Estudo anatômico do encéfalo de avestruz (Struthio Camelus). PUBVET, Londrina, V. 7, N. 7, Ed. 230, Art. 1521, Abril, 2013.

(4) Valécula, (5) Fissura Transversa do cérebro, (6) Lobo óptico, em B) vista lateral (7) bulbo olfatório.

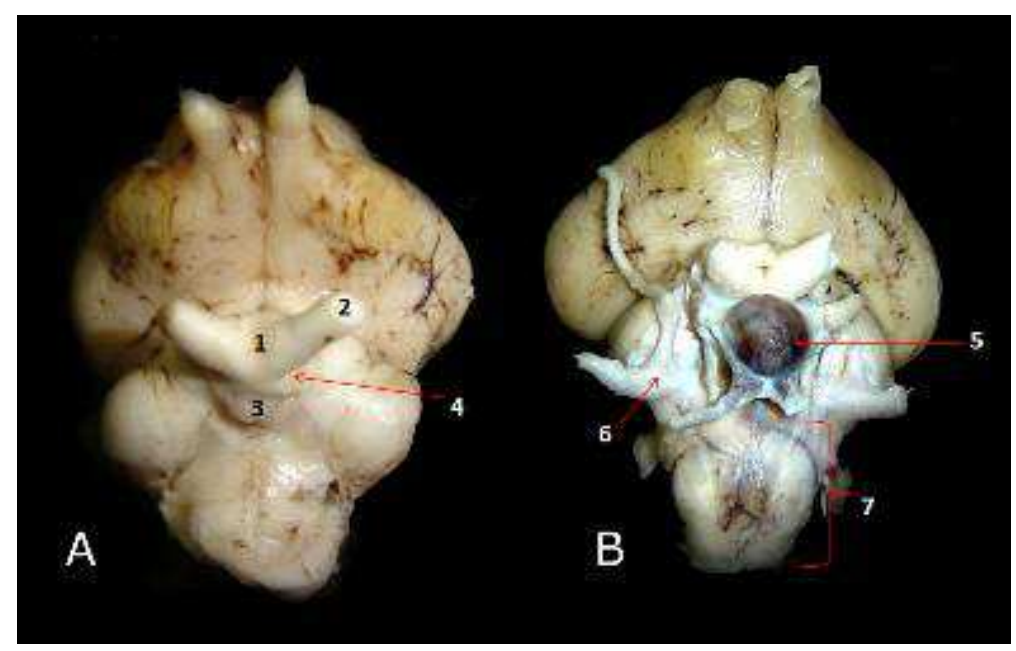

Figura 2. Encéfalo de avestruz na vista ventral. Em na figura $2 A$ observa-se (1) Quiasma óptico, (2) Nervo óptico, (3) Túber cinéreo. A figura 2B evidencia (5) Glândula hipófise, (6) Nervo trigêmeo e (7) Tronco encefálico.

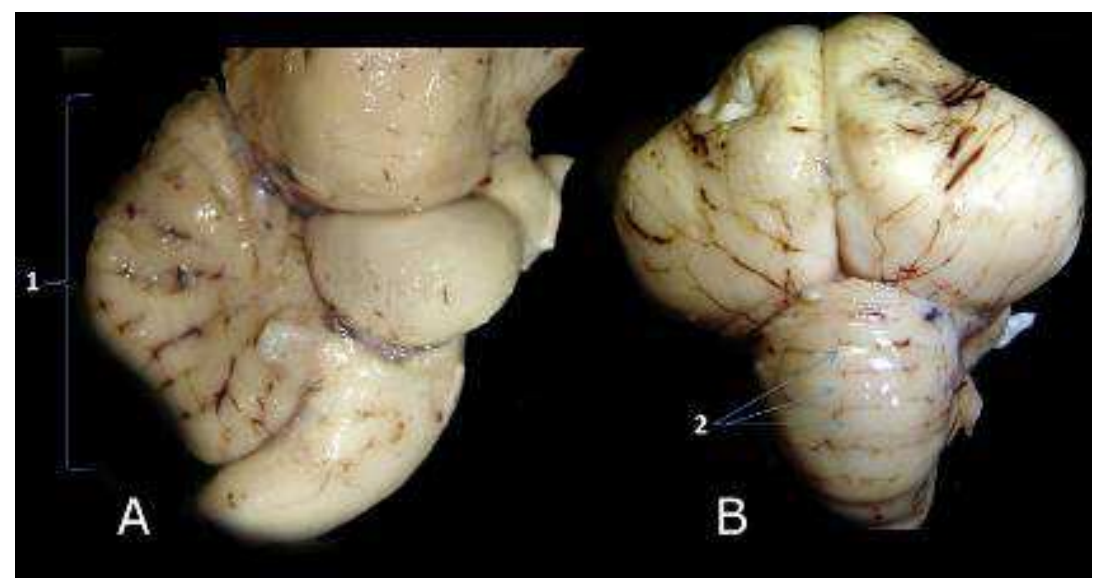

Figura 3. Encéfalo de avestruz. A figura (A) representa a vista lateral do encéfalo de avestruz evidenciando o cerebelo (1). Na vista dorsal figura (B) é representado as folhas cerebelares (2) por indicativo de setas azuis. 
MARQUES, K.V. et al. Estudo anatômico do encéfalo de avestruz (Struthio Camelus). PUBVET, Londrina, V. 7, N. 7, Ed. 230, Art. 1521, Abril, 2013.

\section{DISCUSSÃo}

Com base em nossa extensa literatura consultada sobre encéfalo de aves, constatamos que a maioria dos tratadistas de aves não fazem referências aos aspectos anatômicos do Struthio camelus, utilizam a espécie galiforme como base para todas as aves. Krabbe (1952) descreve que o cérebro da galinha é generalizado como cérebro das aves em geral e algumas vezes comparado com cérebro de répteis, anfíbios e mamíferos. Isso pode ser justificado pelo fato do cérebro das aves apresentarem poucas variações no seu desenvolvimento, e ainda não ser um material de fácil acesso. É interessante demonstrar as diferenças anatômicas entre as várias classes de aves, uma vez que as variam muito em seu tamanho como os minúsculos beija-flores e as aves de grande porte como o avestruz e a ema. O conhecimento das diversas diferenças anatômicas e estruturais dessas aves permite um melhor entendimento da evolução das aves para que possamos entender possíveis diferenciações entre as ratitas, os galiformes, entre outras.

Em nossas observações macroscópicas do encéfalo de avestruz, verificamos que o encéfalo nessa espécie mostrou-se bem desenvolvido, com grandes semelhanças ás estruturas do encéfalo de outras aves quando comparado aos trabalhos de Pearson (1972), Nickel et al. (1977), King e McLelland (1984), os quais realizaram trabalhos de descrições do encéfalo em vários pássaros. É esperado que realmente houvesse essa semelhança nas aves, uma vez que embora representem gêneros e/ou espécies diferentes, integram o mesmo grupo de aves. Entretanto, também são observáveis diferenças no encéfalo do avestruz na superfície ventral, dorsal e lateral em comparação ao de outras aves.

Quando comparamos as fotografias do encéfalo do avestruz feitas por nós com as que constam na publicação de Martin et al.,(2007), relativas ao encéfalo de Emu, Coruja e Pombo, observamos que o avestruz tem um encéfalo mais 
MARQUES, K.V. et al. Estudo anatômico do encéfalo de avestruz (Struthio Camelus). PUBVET, Londrina, V. 7, N. 7, Ed. 230, Art. 1521, Abril, 2013.

definido, com estruturas mais evidentes. Assim, Martin et al.,(2007) relatam que o Kiwi possui um encéfalo grosseiramente comparável com o de Emu, Coruja e Pombo. De fato, embora seja possível encontrar estruturas no encéfalo de aves semelhantes ao de avestruz, também podemos encontrar diferenças.

Martin et al.,(2007), referem que o encéfalo de Kiwi apresenta uma redução da eminência medial quando comparada com Emu, Coruja e Pombo, fato este também comprovado em nossas observações. Podemos ressaltar que apesar do encéfalo do avestruz ser semelhante ao Emu, a Coruja e o Pombo, as estruturas observáveis no avestruz são mais parecidas com as do Emu, provavelmente por pertencerem a mesma classe de aves, ou seja, ratitas. Concordamos com Martin et al.,(2007) ao referirem que as estruturas básicas do encéfalo das aves são filogeneticamente antigas, sobrevindo mudanças por efeito do desenvolvimento de algumas estruturas e de interpelações estabelecidas, com outras partes do sistema nervoso central. Particularmente o progressivo aumento do lobo óptico que no Kiwi é menor quando comparado ao do avestruz, ao Emu, a Coruja e o Pombo. Essas modificações provavelmente são em relações estabelecidas pelas funções do lobo óptico nessas espécies. O Emu apresenta hábito diurno, Kiwi, noturno, Coruja (noturno) e Pigeon (diurno), essa relação de hábitos interfere na organização estrutural dos seus encéfalos. Dada à relação do Kiwi, uma espécie de ratita, mas de pequeno porte, com o Moa uma espécie de ratita de grande porte que foi extintas no século XVI, e o avestruz uma ratita também de grande porte. A Moa e o avestruz apresentam olhos grandes, daí a notável grandeza dos lobos ópticos nessas duas espécies de ratitas. Já no Kiwi apesar de também ser uma ratita não apresenta um lobo óptico grande quando comparado com a Moa, o Avestruz e o Emu (Jeffery, 2005).

A evolução no lobo óptico das aves é interessante uma vez que as aves apresentam-se mais desenvolvidos a audição e a visão. O nervo óptico é o maior de todos os outros nervos craniais, refletindo o grande desenvolvimento da visão 
MARQUES, K.V. et al. Estudo anatômico do encéfalo de avestruz (Struthio Camelus). PUBVET, Londrina, V. 7, N. 7, Ed. 230, Art. 1521, Abril, 2013.

nas aves. O nervo óptico é particularmente grande nas espécies dos falcões e corvos e relativamente pequeno nas aves noturnas (King e McLelland,1984). No avestruz o nervo óptico tem um grande tamanho.

Já o bulbo olfatório é uma estrutura que apresenta um grau de desenvolvimento reduzido nas aves (Nickel et al., 1977), fato esse que podemos comprovar no trabalho de Martin et al.,(2007), com as fotografias apresentadas por eles, o bulbo olfatório mostra-se bastante reduzido. No avestruz o bulbo olfatório é pequeno quando comparado com as demais estruturas do encéfalo.

Em relação à superfície do encéfalo do avestruz, esse se demonstra com algumas irregularidades, notadas pela presença da eminência medial e a vallécula. Nas fotos de Martin et al.,(2007), quando comparadas com as nossas do avestruz, podemos verificar que o Emu, o avestruz, a Coruja e o Pombo apresentam essas estruturas. Já no Kiwi encontram se ausentes tanto a eminência como a valécula, sendo essas duas estruturas mais salientes no avestruz e no emu.

Particularmente em relação ao diencéfalo, pode-se se afirmar que o quiasma óptico, hipófise, infundíbulo e os III e IV nervos cranianos são semelhantes às descrições de Nickel et al. ,(1977) e King e McLelland (1984). O diencéfalo é uma estrutura média entre telencéfalo e tronco encefálico. Em vista dorsal é possível observar a glândula pineal. Na ave doméstica este é uma estrutura em forma cônica de coloração rósea, situada em um espaço triangular delimitados pelos hemisférios cerebrais e o cerebelo com aproximadamente 3,5 $\mathrm{mm}$ de comprimento e $2,0 \mathrm{~mm}$ de largura. Na face rostral a principal característica do diencéfalo é o quiasma óptico, constituído a partir do cruzamento dos tratos ópticos esquerdos e direito. A glândula hipófise faz parte do diencéfalo e está situada na porção caudal do quiasma óptico e King e McLelland (1984). 
MARQUES, K.V. et al. Estudo anatômico do encéfalo de avestruz (Struthio Camelus). PUBVET, Londrina, V. 7, N. 7, Ed. 230, Art. 1521, Abril, 2013.

Em correspondência ao plano rostral, verificamos a presença de um sulco, a fissura rostral. No avestruz essa estrutura não demonstra-se interrompida pela decussão das pirâmides. Com relação aos vertebrados, a fissura rostral é constante em humanos (Crosby et al.,1962) e e também em aves Pearson (1972), Nickel et al. (1977) e King e McLelland (1984). Em posição lateral à fissura mediana rostral, não verificamos no avestruz a presença de olivas e pirâmides que são evidentes em outros vertebrados como o homem (Crosby,1962). As olivas e pirâmides também não são descritas nos trabalhos de Pearson (1972), Nickel et al. (1977) e King e McLelland (1984).

De modo geral o tronco encefálico do avestruz, apresenta o sulco mediano, os pedúnculos cerebelar médio e inferior, o véu medular superior e o véu medular inferior. A ponte apresenta o nervo trigêmeo e o pedúnculo cerebelar médio em sua face rostral. O tronco encefálico do avestruz possui estruturas semelhantes as descritas nos trabalhos de Nickel et al,(1977) e King e McLelland (1984), que descreveram o encéfalo de aves, porém não enfatizaram o cérebro do avestruz.

No avestruz o cerebelo é bem delimitado e semelhante ao do homem e ao galo doméstico (Chowdhury e Ghosh, 2003). Embora o cerebelo de ambas as espécies galo, homem e avestruz, apresentem características anatômicas semelhantes, podemos verificar que existem variações no que concerne a sua morfologia. O cerebelo do avestruz é grande, assim como o do galo e do humano. Kappers et al., (1936), descrevem que o cerebelo grande é sinal de que nas aves ocorre um aumento do número de feixes de fibras espinocerebelares. Autores como Parker e Haswell (1963) mencionam que cerebelo grande em pássaros está associado com o centro de equilíbrio das aves. Chowdhury e Ghosh (2003) descrevem que o cerebelo do galo situa-se caudal aos hemisférios cerebrais e dorsal a medula oblonga e ponte, embora no homem essa posição seja considerada caudodorsal. Messer (1958) relata que o cerebelum das aves está próximo ao telencéfalo e recobre o diencéfalo. 0 cerebelo do avestruz apresenta 
MARQUES, K.V. et al. Estudo anatômico do encéfalo de avestruz (Struthio Camelus). PUBVET, Londrina, V. 7, N. 7, Ed. 230, Art. 1521, Abril, 2013.

posicionamento semelhante ao descrito por Chowdhury e Ghosh, (2003). Concordamos com Chowdhury e Ghosh (2003), quando esse também descreve que entre o cerebelo e o tronco encefálico situa-se o quarto ventrículo.

Os hemisférios cerebelares do avestruz são bem desenvolvidos e o vermis do cerebelo é reconhecido. O arranjo do cerebelo é semelhante ao de outros vertebrados ainda de acordo com Nickel et al (1977), a divisão do cerebelo em lobos cerebelares são nomeadas em relação as semelhanças do cerebelo dos mamíferos. O cerebelo apresenta uma organização em lóbulos que são reconhecidos como superior médio e inferior (Chowdhury e Ghosh, 2003). Esse arranjo é parecido com o descrito por Larsell e Whitelock (1952) que observaram um grau de diferenciação nos lobulos das aves. No avestruz encontramos essas semelhanças com os achados de Chowdhury e Ghosh, (2003), para o Galo e Larsell e Whitelock (1952), para os pássaros. Ranson e Clark (1959) descreveram que o vermis cerebelar é altamente desenvolvido nos pássaros que voam quando comparados com os que não voam (emu, avestruz, kiwi). Iwaniuk et al.,(2006), descrevem que segundo a filogenia das aves, existe uma diferenciação das folhas cerebelares entre as espécies, os corvos, os papagaios e as aves marinhas apresentam cerebelo com maior número de folhas cerebelares, isso provavelmente devido a filogenia das espécies que apresentam maior grau de cognição e diferenças comportamentais entre as aves. Para Nickel et al., (1977) o cerebelo é órgão da locomoção, manutenção, equilíbrio e consequentemente tem um tamanho considerável, sendo um padrão de diferenciação nas aves. Nas folhas cerebelares do avestruz é possível identificar em cortes sagitais a língula, lobo central, culmen, declive, folium do verme, tuber do vermes, pirâmide, úvula e o nódulo que relembram as características do cerebelo de pássaros (Nickel et al, 1977; Iwaniuk et al.,(2006) e do galo (Chowdhury e Ghosh, 2003). 
MARQUES, K.V. et al. Estudo anatômico do encéfalo de avestruz (Struthio Camelus). PUBVET, Londrina, V. 7, N. 7, Ed. 230, Art. 1521, Abril, 2013.

\section{Conclusão}

Do que acabamos de expor julgamos poder concluir que:

1- A organização geral das estruturas componentes do encéfalo de avestruz enquadra-se no pradrão característico de outras aves.

2- No telencéfalo do avestruz, mostram-se bem marcadas as seguintes estruturas: valécula, eminência medial, fissura longitudinal e bulbo olfatório.

3- No diencéfalo em sua face rostral, aparecem bem marcados: quiasma óptico, nervo óptico, trato óptico, hipófise.

4- O tronco encefálico é definido sendo possível reconhecer o mesencéfalo, ponte e bulbo.

5- O IV ventrículo apresenta bem marcado, assim como o sulco mediano e véus medulares (superior e inferior).

6- O cerebelo apresenta folhas cerebelares e sulcos semelhantes à de outras aves.

7- Considerando os dados da literatura consultada, relativos a outras espécies de aves, o encéfalo do avestruz mostra disposições características de algumas de suas estruturas que são consideradas indicadores de evolução, tais sejam: lobo óptico, origem aparente de nervos cranianos, fissuras lobulares do cerebelo. 


\section{REFERÊNCIAS}

BAER, K. E. V. Über Entwickelungsgeschichte der Thiere. Beobachtung und Reflexion, Bde. 2, Borntraeger, Königsberg (1828/1837).

Chowdhury PB, Ghosh RK. Comparative anatomical study of the cerebellum of man and fowl. J Anat Soc India. 2003; 52(1):32-7.

Crosby EC, Humphrey T, Lauer EW. Correlative anatomy of the nervous system. New York: Macmillan. 1962.

Jeffery WR (2005) Adaptive evolution of eye degeneration in the Mexican blind cavefish. J Hered 96: $185-196$

Giannoni, M.L. Viabilidade da exploração de ratitas em São Paulo. Biológico, São Paulo, v.1, n.2, p.91-96, jul./dez,1998.

Iwaniuk, A.N., Hurd, P.L., and Wylie, D.R.W. Comparative morphology of the avian cerebellum: I. Degree of foliation. Brain, Behavior and Evolution, 68, 45-62. 2006.

Kappers C. U. A. et al : The cerebellum. In the comparative Anatomy of the Nervous system of vertebrates including man Vol. II. Haffner Publishing Company, New York : pp 696-860. 1936.

King AS, McLelland J. Birds Their Structure and Function, 2nd ed. The Pitman Press, Great Britain. 218-220. 1984.

KUPFFER, C. V. Die Morphogenesis des Centralnervensystems. In Handbuch der vergleichenden und cxperimentellen Entwickelungslehre der Wtrbeltiere (ed. O. Hertwig). Bd. 2 Teil 3. Gustav Fischer, Jena. 1906.

KRABBE, K.H. Studies on the morphogenesis of the brain in birds (Morphogenesis of the vertebrate brain V). Ejnar Munksgaard, Copenhagens, 1952.

KRABBE, K.H. Studies on the morphogenesis of the brain in Struthio Camelus. Munksgaard, Conpenhagem. 1956.

Larsell, O., and Whitelock, D. G. Further observations on the cerbellum of birds Journal of comparative Neurology. 97 : 545-566. 1952.

Martin GR, Wilson KJ, Martin Wild J, Parsons S, Fabiana Kubke M, Corfield J.Kiwi forego vision in the guidance of their nocturnal activities. PLoS One. Feb 7;2(2):e198. 2007.

Messer, H.M. The Nervous System. In: An Introduction to veterinary Anatomy. The Macmillan Company, New York : pp 374-380. 1958.

NICKEL, R.; SCHUMMER, A.; SEIFERLE, E. Anatomy of the domestic Birds. Hamburg: Parey, p.115-127, 1977.

Parker, T.J. and Haswell, W.A. : Textbook of Zoology In : Vertebrates Vol-2, 7th Edn. Macmillan \& Co. Ltd, London. pp 312, 410, 542, 592, 681. 1963. 
PEARSON, R. The avian brain. Academic Press. New York. 1972.

Ranson, S.W. and Clark, S.I: (1972). The Anatomy of the Nervous System - its development and function 10th Edn. W.B Saunders Co. Philadelphia. PP 43-45 and 286-287. (1959)

SICK, H. 1997. Ornitologia brasileira. Rio de Janeiro, Editora Nova Fronteira, 912p.

ZIMMERMANN (1891). Uber die Metamerie des Wirbeltierkopfes. Vcrhandl. d. Anat. Ge 